\title{
Susceptibility versus resilience to mountain hazards in Austria - paradigms of vulnerability revisited
}

\author{
S. Fuchs \\ Institute of Mountain Risk Engineering, University of Natural Resources and Applied Life Sciences, Vienna, Austria \\ Received: 1 December 2008 - Revised: 12 January 2009 - Accepted: 21 February 2009 - Published: 13 March 2009
}

\begin{abstract}
The concept of vulnerability is pillared by multiple disciplinary theories underpinning either a technical or a social origin of the concept and resulting in a range of paradigms for either a qualitative or quantitative assessment of vulnerability. However, efforts to reduce susceptibility to hazards and to create disaster-resilient communities require intersections among these theories, since human activity cannot be seen independently from the environmental setting. Acknowledging different roots of disciplinary paradigms, issues determining structural, economic, institutional and social vulnerability are discussed with respect to mountain hazards in Austria. It is argued that structural vulnerability as originator results in considerable economic vulnerability, generated by the institutional settings of dealing with natural hazards and shaped by the overall societal framework. If vulnerability and its counterpart, resilience, is analysed and evaluated by using a comprehensive approach, a better understanding of the vulnerability-influencing parameters could be achieved, taking into account the interdependencies and interactions between the disciplinary foci. Thereby the overall aim of this paper is not to develop another integrative approach for vulnerability assessment, different approaches are rather applied by using a vulnerability-of-place criterion, and key issues of vulnerability are reconsidered aiming at a general illustration of the situation in a densely populated mountain region of Europe.
\end{abstract}

\section{Introduction}

Following the axiom that natural hazard risk is a function of hazard and consequences, the ability to determine vulnerability either quantitatively or qualitatively is an essential pre-

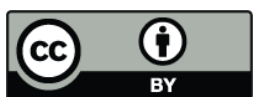

Correspondence to: S. Fuchs

(sven.fuchs@boku.ac.at) requisite for reducing these consequences and therefore natural hazard risk. The assessment of vulnerability requires an ability to both identify and understand the susceptibility of elements at risk and - in a broader sense - of the society to these hazards (Birkmann, 2006a). Studies related to vulnerability of human and natural systems to mountain hazards, and of the ability of these systems to adapt to changes in the functional chain of hazards, are a relatively recent field of research that brings together experts from a wide range of disciplines, including natural science, development studies, disaster management, health, social science, policy development and economics, to name only a few areas. Researchers from these fields bring their own conceptual models to study vulnerability and adaptation, models which often address similar problems and processes using different languages (Brooks, 2003).

With respect to mountain hazards, the concept of risk emerged as an appropriate concept to deal with vulnerability in recent decades (e.g., Borter, 1999; Kienholz et al., 2004), even if the roots trace back to very early influential works by the Chicago school (Kates, 1962; White, 1964; Burton et al., 1978, 1993). Spatiotemporal-based research into natural hazards began with attempts to explain the rising level of flood damage in the US in conjunction with unprecedented efforts and expenditures to control them (White, 1945; White et al., 1958). Some of White's most notable work (White, 1945) was a particular benchmark in stimulating subsequent studies, and involved the identification and classification of adjustment mechanisms for flooding in the US, perceptions of natural hazards, and choice of natural hazard adjustments (Hinshaw, 2006). Hence, even before the leading work published by Starr (1969), from the point of view of geosciences the attempt was made to investigate human adjustments to risk and associated vulnerability. The main point in this early research is the differentiation between extreme natural events and the actual natural hazards that impinge upon spheres of human interests, which provided material for the

Published by Copernicus Publications on behalf of the European Geosciences Union. 
vulnerability discussion up to the present time. White (1945) identified adjustments to flooding as being either structural or non-structural. He advocated, where feasible, adaptation to or accommodation of flood hazards rather than the structural and permanent mitigation measures (e.g., dams, levees, and floodwalls) that dominated policy in the early 20th century. In particular non-structural adjustments, consisting of arrangements imposed by a governing body (local, regional, or national) to restrict the use of floodplains, or flexible human adjustments to flood risk that do not involve substantial investment in flood controls, still remain central with respect to the contemporary management of hazards and risk in mountain catchments (Tobin and Montz, 1997; Commission of the European Communities, 2007). Following Atkisson et al. (1984), private and public adjustments to reduce vulnerability to such hazard events consist largely of fixed investments (flood control structures, torrential barriers, etc., Fuchs and McAlpin, 2005), while other involve primarily recurrent expenses for personnel (avalanche warning services, Fuchs et al., 2007a). While some adjustments are inherently public (zoning regulations, Kanonier, 2006), others are private (local structural protection, Holub and Hübl, 2008). Some involve physical interference with the actual natural event (technical protection in the starting zones), while others are merely attempts to reduce the effects of natural variations (retention basins with grain-sorting outlet structures), and still others involve only the control of human society (evacuation).

The term vulnerability is closely related to natural hazards, and is conceptualised in hazard and disaster management in various ways. As a consequence, the notion of vulnerability is as divergent as the methods and theories of disciplines involved in risk research. Social scientists and engineers or natural scientists often address different issues when they use the term vulnerability. Whereas social scientists tend to view vulnerability as representing the set of socio-economic factors that determine people's ability to cope with stress or change (Allen, 2003), engineers often view vulnerability in terms of the likelihood of occurrence of specific process scenarios, and associated impacts on the built environment (e.g., Varnes, 1984). Thus, the consequences of natural hazards are generally measured in terms of damage or losses, either on an ordinal scale based on social values or perceptions and evaluations, or on a metric scale (e.g., in monetary units). Consequently, diverse perspectives on the concept of vulnerability exist; major approaches include the perspective from social science, the perspective from economics and the perspective from natural science. More general, the characteristics of the vulnerable system, the type and number of stressors and underlying causes and effects, the consequences on the system and the temporal dimension of impact (Kasperson et al., 2005) define the framework for vulnerability assessment when managing natural hazard risk.

However, apart from the overall discussion on linguistic and semantic dimensions of the term (e.g., Cutter et al., 1996;
Cutter, 2003; Alexander, 2005), vulnerability in the context of mountain natural hazards in Europe is from a practitioner's side - e.g. the Austrian Torrent and Avalanche Control Service - usually defined as the physical impact of hazardous events on elements at risk. Accordingly, if quantitatively assessed, vulnerability is defined as the expected degree of loss for an element at risk, occurring due to the impact of a defined hazardous event. These events are themselves conditioned by a certain intensity, frequency and duration, all of which affect vulnerability. This perspective from natural scientists is focussing on impact intensities and structural susceptibilities, ranging from 0 (no damage) to 1 (complete destruction) during the sets of calculations (e.g., Varnes, 1984). From this technical point of view, vulnerability assessment is based as a general rule on the evaluation of several parameters and factors such as building categories or types, construction materials and techniques, state of maintenance, presence of protection structures, presence of warning systems and so on (Fell, 1994; Fell and Hartford, 1997). For this reason, vulnerability values describe the susceptibility of elements at risk facing different process types with different spatial and temporal distributions of process intensities (e.g., flow depths, accumulation heights, flow velocities and pressures).

Within the domain of social sciences, a distinct conceptual separation between vulnerability, hazard and risk can be observed. Vulnerability is understood as a predisposition and potential of society or individuals to be harmed, consequently, vulnerability does not change if the hazard is more intense or not - it is in contrast the exposure that might change and that influences the degree of being at risk. Approaches of vulnerability assessment not only differ between several degrees of voluntariness when being prone to natural hazards, but also consider individual as well as social influences, filtered by certain conditions that determine an individual's perception of risk. Depending on various guiding elements such as probability of occurrence, extent of damage, perception, uncertainty, ubiquity, persistence, reversibility, time delay, and mobilisation potential (Renn, 2008 based on WBGU, 1998), the degree of vulnerability may considerably change. A major challenge in vulnerability research is that "not only people are different, but they are changing continuously, both as individuals and as groups. This constant change within the human system (...) interacts with the physical system to make hazard, exposure, and vulnerability all quite dynamic" (Mileti, 1999, p. 119). These changes lead to the postulate that the only consideration of either structural vulnerability, subject to the domain of natural scientists, or social vulnerability, subject to the domain of social scientists in a broader sense, is not sufficient to assess vulnerability comprehensively from an integrative point of view. In contrast, dimensions of susceptibility, presumably starting with the physical impact on elements at risk defined as structural vulnerability, further encompass institutional, economic, and social aspects. Thereby, any damage occurring might be con- 
sidered as prerequisite for structural and economic susceptibility, while institutional susceptibility and social aspects provide the framework for vulnerability in general. In this manner, multiple interactions between these conceptualisations of vulnerability exist.

Although not specifically focused on vulnerability, considerable theoretical work in hazard research provides insight into the cultural, social, and political processes operating if societies are faced with mountain hazards. According to Kasperson et al. (2005), cultural theory offers an interpretation into how cultural biases enter into the types of hazards that are dealt with and the types of coping strategies and management systems that are employed. Moreover, the social amplification of risk (Kasperson et al., 1988; Pidgeon et al., 2003) provides a conceptual framework for examining the social and political processes by which societies process risks. In addition, the scholars of critical theory understand natural hazards in terms of social conditions forcing people to live in endangered areas and simultaneously reduce their coping capacity for managing the hazard. In this sense mountain hazards, understood as perturbations or stressors, are a social construction in which different social units are differently exposed and therefore have different coping capacities. These approaches are based on the belief that no individual or group would chose a more hazardous or risk-prone setting, and do so only when other options are unavailable or unattractive. In a global context, the more marginal economically and the weaker politically, the fewer the options, the more likely is the environment to be hazardous, and the greater are the difficulties in coping with stresses and perturbations (Wisner, 2000, 2004). In contrast, and funnelling down to a regional scale, the diversity of conceptualisations of the vulnerability concept leads to the question of whether or not people in European mountain regions are vulnerable to natural hazards, and how vulnerability could be addressed in the intersection between engineering approaches (technical vulnerability), institutional vulnerability, economic vulnerability, and social vulnerability. The overall aim of this paper is not to present another integrative approach, different approaches emerging from social sciences and natural sciences will rather be applied to the situation in Austria, and the arguments on vulnerability issues will be discussed following a vulnerability-of-place approach. This approach is based on recent work by Cutter et al. (1996, 2008), locating local and regional vulnerability due to the exposure to hazard events within the larger (institutional) context that influence susceptibility. By bridging the gap between different disciplinary foci, key issues of vulnerability to mountain hazards and underlying paradigms will be reconsidered taking torrent events and associated processes as an example. By putting the geographical focus on Austria, different dimensions of vulnerability and associated interactions will be highlighted.

\section{Structural vulnerability}

Taking the perspective of natural sciences, and neglecting any social implications arising from mountain hazards, vulnerability is considered as a functional relationship between process magnitude or intensity, the resulting impact on structural elements at risk, and exposed values. With respect to the built environment, vulnerability is related to the susceptibility of physical structures and is defined as the expected degree of loss resulting from the impact of a certain (design) event on the elements at risk. Its assessment requires the evaluation of different parameters and factors such as type of element at risk, resistance, and implemented protective measures (i.e., local structural protection). With respect to the hazardous processes, empirical parameters such as magnitude and frequency have to be evaluated based on probability theory. Thereby the magnitude-frequency concept plays a key role. When the activity of different hazard processes is compared on a given timescale some processes appear to operate continuously while others operate only when specific conditions occur. The term eposidicity was used by Crozier (2004) to refer to the tendency of processes to exhibit discontinuous behaviour and to occur sporadically as a series of individual events. Episodicity appears when discontinuity is inherent in the forcing process, however, with respect to mountain hazards, the relationship between the initiating forcing process (e.g., intense but discontinuous rainfall) and the geomorphic response (e.g., formation of debris flows as a result from erosion and mobilisation of solid particles in a channel bed) is not constant. Operationally, triggering thresholds are used instead to indirectly approach the probability of occurrence of a specific design event, and connectivity is assumed to deduce the behaviour of the hazard process from that of the triggering factor itself.

By applying the concept of risk, the definition of vulnerability plays an important role in natural hazards research within mountain environments (Fuchs et al., 2007b). Hence, from an engineering point of view, considerable areas in European mountain regions are vulnerable to hazard processes. Even if the theory of vulnerability had been subject to extensive research and numerous practical application for the last decades, considerable gaps still exist with respect to standardised functional relationships between impacting forces due to occurring hazard processes and the structural damage caused. For a major part these gaps result from the overall lack of data, in particular concerning (1) losses caused by mountain hazards as a result of outstanding empirical classifications of damages and (2) impact forces that caused these losses. Consequently, possible losses due to future events can only be predicted so far at the basis of relatively sporadic empirical classifications.

Recently, promising approaches for a quantification of structural vulnerability have been made by Wilhelm (1997), Borter (1999) and Barbolini et al. (2004) with respect to avalanches and rock fall processes, respectively. These sug- 
gestions are based on (partially estimated) empirical relations between impact forces (e.g., pressure, accumulation height) and observed damage to exposed buildings located in the respective run-out areas.

Further suggestions for a vulnerability-intensity relationship for the application in torrent risk assessment have been made by Fuchs et al. (2007b) based on case studies in Austrian torrent catchments, these have been extended by additional Swiss data (Kimmerle, 2002), see Fig. 1. The applied method followed a spatial approach, and was based on accumulation heights as a proxy for process intensities, spatial data from elements at risk and average reconstruction values in dependence of the surface area on an object basis. The relationship between process intensity $x$ and vulnerability $y$ was found to fit best to the data by a second order polynomial function for all intensities $0.33 \leq x \leq 3.06 \mathrm{~m}$, see Eq. (1). The coefficient of determination $R^{2}$ is 0.97 , which seems to be comparatively sound with respect to the amount of data available.

$f_{(x)}=\left\{\begin{array}{lll}0 & \text { if } & x<0 . \overline{3} \\ 0.12 x^{2}-0.04 x & \text { if } & 0 . \overline{3} \leq x \leq 3.06 \\ 1 & \text { if } \quad x>3.06\end{array}\right.$

In addition, the analysis of the data had shown that the vulnerability of buildings affected by medium process intensities $(1.00-1.50 \mathrm{~m})$ is highly dependent on whether or not the entrained material harms the interior of the building (i.e., by an intrusion of material through openings such as doors, wells and windows). Consequently, local protection measures such as deflection walls and specially designed closure structures for at-grade openings definitely play a major role in reducing the vulnerability of buildings, particularly with respect to low and medium process intensities.

Even if such empirical relationships become increasingly important in determining vulnerability of structural elements at risk, and they are deduced by using individual object data, the overall principle is connected to a spatial application of the mathematical formulae. As a consequence, the results mirror the average expected systems behaviour (expected destruction due to impacting forces) for a certain amount of values at risk, e.g., the entire area of a torrent fan or an avalanche run-out area presumably affected by a defined 1 in 150 year event. However, this design event does not cover the entire possible run-out area, but only a certain part of it. This assumption is based on the repeatedly observation that the individual design event accumulates in a lobe-shaped pattern, in particular if the accumulation area is convex (see Fig. 2). Hence, the spatial probability of occurrence of individual scenarios may be neglected during the application of vulnerability-intensity relationships, and is continuously taken into account by applying overall spatial reduction factors during operational risk analyses (e.g., BMLFUW, 2005). Furthermore, since resistance against impact forces is dependent on the construction type of buildings which typically to be identified by field studies, determining structural vulnerability is very time-consuming and thus costly. Furthermore, the effects of processes in the run-out area is not yet completely known ${ }^{1}$, consequently, modelled impact pressures can only be a rough estimate of the real system behaviour. With respect to mountain hazards, there were examples where an avalanche destroyed a building situated perpendicular to the avalanche axis (e.g., in the hamlet of Valzur, Paznaun, Austria, in February 1999), but there were cases where such a building was able to stop such an avalanche completely (e.g., in the village of Airolo, Ticino, Switzerland, February 1951). To conclude, the component of structural vulnerability within risk analysis for mountain hazards is still roughly specified, mainly due to a lack of intensive experimental or observational data. Nevertheless, within the present study, structural vulnerability is understood to be the source for any other vulnerability concept, since if there was no impact due to a hazardous event on elements at risk, no loss would result, and the society as a whole would not suffer harm.

\section{Institutional vulnerability}

If the concept of vulnerability is defined by an anthropocentric concept, human behaviour is connected to the effects of natural hazards. Accordingly, individuals have a set of choices to reduce exposure and decrease vulnerability that is determined by a framework consisting of the prevalent political system and related institutional structures. Hence, the perspective of institutional vulnerability is framed by the socio-political, cultural, and economic factors that together determine differential exposure to hazards and associated impacts, and differential capacities to recuperate from past impacts and to adopt future threats (Eakin and Luers, 2006). The concept of institutional vulnerability emphasises the human-environment interaction, and is defined as a state or condition of being moderated by existing inequities in resource distribution and access, a well as prevalent historical patterns of social domination and marginalisation (Eakin and Luers, 2006), being synthesised in the Pressure and Release model of Wisner et al. (2004). With respect to the assumed aim of individuals to reduce vulnerability, and taking into account the relative complexity of understanding vulnerability to natural hazards, this set of choices is for a large part as-

\footnotetext{
${ }^{1}$ Future research concerning the behaviour of processes in the run-out areas is needed, in particular related to the structure of buildings. Buildings can have similar effects on hazard impacts as retarding mounds used for technical mitigation. Thus, due to a shift in the building pattern within the accumulation area (Fuchs et al., 2004, 2005), buildings oriented towards the valley bottom tend to result in smaller risk than buildings that are located closer towards the transit area. Independent from the related political implications and the associated impacts on land-use planning, further studies on this effect should be carried out due to the probable reduction of the run-out areas and, as a consequence, the resulting risk.
} 


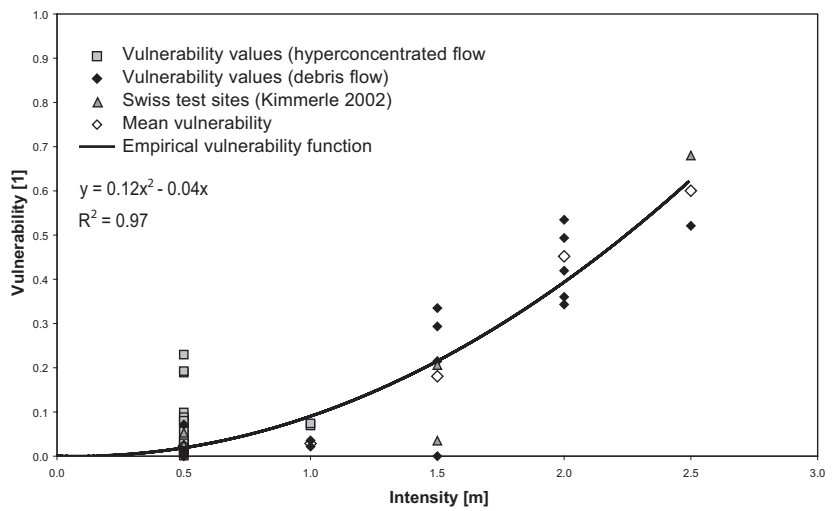

Fig. 1. Empirical vulnerability function for torrent processes in Austria. Data related to debris flows is shown by solid black rhombi (mean by framed white rhombi). Data from Swiss test sites (Kimmerle, 2002) is presented by grey triangles. Data originating from hyperconcentrated flows is shown by grey squares. Adopted and modified from Fuchs et al. (2007b, p. 502).

signed to the political decision maker. As a result, in Austria, individual precaution is increasingly neglected, and institutions take over the responsibilities of decisions and actions to mitigate natural hazard risk and decrease vulnerability. Such decisions and actions include efforts to (1) reduce the probability of occurrence of potentially damaging processes, which is mainly attributed to the strategy of permanent mitigation and had been institutionally taken over for decades by the Torrent and Avalanche Control Service in Austria (Stötter and Fuchs, 2006; Holub and Fuchs, 2009), and (2) reduce the adverse effects of natural hazard processes by shifting the probability of loss to a larger community, e.g. by taking out an insurance policy.

Following Frey (1990), institutions can be classified into three types due to different prevalent aspects:

1. Institutions defined as procedures and systems by means of which decisions are made within a society. Major systems include the market (from an economic point of view), the political system of democracy, other negotiating systems such as streamlined hierarchies, and the associated procedures of action.

2. Institutions defined as formal and informal rules that determine human action, such as the legal system, determined by the respective political entity, the traditional framework established due to religion, and social norms developed though history.

3. Institutions defined as organisations, such as the overall state structure, organisations and bureaucracies, but also clubs, the family and informal groups of individuals that share a common aim.

According to North (1990), these institutions shape the rules within a society and among different societal stakeholders;

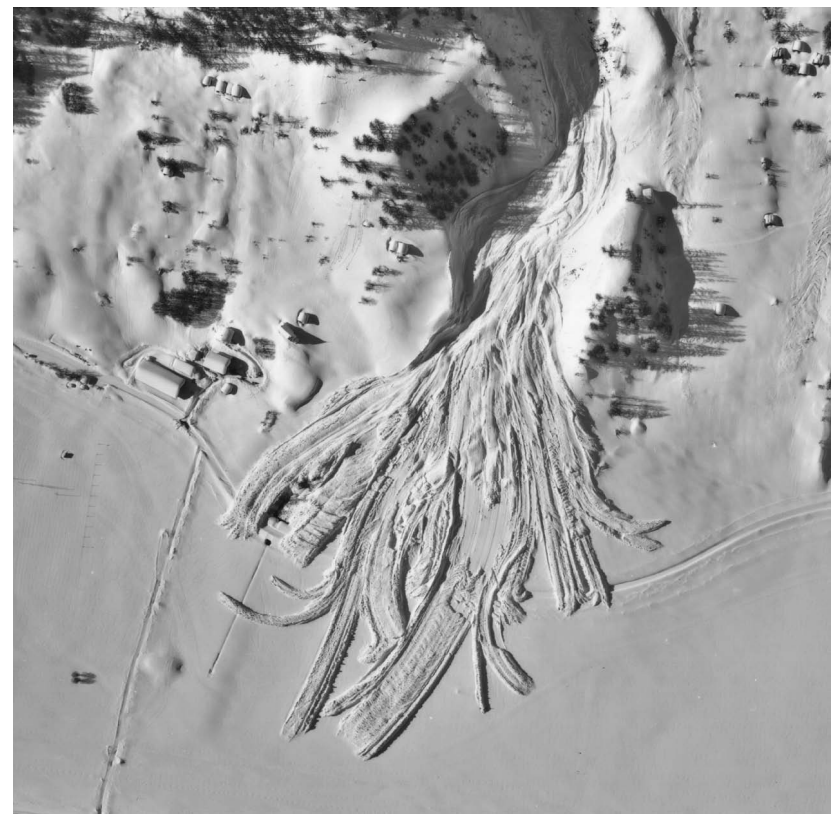

Fig. 2. Finger-shaped avalanche accumulation during the winter 1998/99 westwards of the municipality of Ulrichen, Valais, Switzerland. Reproduced with permission of the Swiss Federal Office of Topography, Center for the Coordination of Aerial Photography (Fuchs and McAlpin, 2005).

and with respect to vulnerability these institutions are of considerable importance to reduce the effects of natural hazards for individuals and the society. Thereby, the overall principle of action is given by the rational choice theory: The basic idea of this theory is that patterns of behaviour in societies reflect the choices made by individuals as they try to maximise their benefits and minimise their costs (e.g., Scott, 2000). Hence individuals make decisions on how they should act by comparing the costs and benefits of different possibilities to act. As a result, patterns of behaviour are developed within the society that result from these choices. In Austria the institutional setting in dealing with risk is pillared by the overall principle of governmental responsibility for mitigating natural hazards. However, issues related to an institutional reduction of vulnerability are not explicitly taken into account so far: Firstly, the legislation related to natural hazards is diverse due to the federal structure of the Republic of Austria. Several articles at the federal level are supplemented by various regulations on the level of federal states (Länder level) and even below at community level, in particular with respect to land use planning. Secondly, risk awareness is not very prevalent throughout the country due to an information deficit related to (1) the general occurrence of mountain hazards and (2) mitigation strategies and concepts to avoid losses. Thirdly, different strategies to mitigate and thus compensate the effects of mountain hazards exist in Austria. These strategies, above all the governmental disas- 
ter fund and private insurance solutions, are neither particularly coordinated with respect to risk minimisation nor do they create considerable incentives for individuals to prevent losses, which will be discussed in the following paragraphs in more detail.

It has been argued by several authors that besides political bodies and subordinated public authorities - often due to the respective legal framework - an insurance system could be a promising institutional setting in order to reduce vulnerability resulting from natural hazards (for a compilation see Ungern-Sternberg, 2004; Fleischhauer et al., 2006). However, it has been claimed by other studies that the institutional framework of insurances against natural hazards is only a sub-optimal solution, in particular since the market for insurance works imperfectly or fails completely. The overall reason for these shortcomings can be ascribed to the phenomena of adverse selection and moral hazard (e.g., Jaffee and Russell, 2003; Raschky, 2008), both of these phenomena are applicable in Austria due to a non-mandatory insurance system against natural hazards (Holub and Fuchs, 2009). Adverse selection is defined as the adverse impact on an insurer when risks are selected that have a higher probability of loss than that contemplated by the applicable insurance rate. Adverse selection occurs in the prevailing system of mitigating hazards in Austria since only those persons and business entities being located in endangered areas tend to contract insurances. Moral hazard is the phenomenon that individuals behave in ways to satisfy themselves, but their behaviour comes at the detriment of others because they do not bear the full cost. The phenomenon of moral hazard with respect to mountain hazards describes a situation in which a person partly protected by any loss compensation system may be less vigilant about negative consequences resulting from hazard impacts, because these negative consequences are (partially) borne by the compensation system.

This market failure led to alternative institutional settings in Austria, namely different forms of governmental intervention in order to guarantee for a certain disaster assistance, compensation or governmental aid. Hence, in countries without mandatory insurance coverage such as Austria, risk-transfer lies within the responsibility of political institutions $^{2}$. Internationally, government compensation is a proven solution to recouping flood losses (Arnell, 2000), however, effectiveness is varied, schemes are often inefficiently administered and decisions politically motivated (Priest et al., 2005). Apart from this overall criticism, any adoption of government compensation alongside an existing commercial hazard insurance industry is reported to be counterproductive, as it would act as a major disincentive towards indi-

\footnotetext{
${ }^{2}$ Another option could theoretically be not to decide for any formalised risk transfer, and consequently compensation that is not formally organised through an insurance company or a government could take place. In fact such informal risk transfer systems, e.g. between relatives, are quite common in less developed countries.
}

viduals purchasing their own insurance (Gruber, 2008). The tendency of individuals not to insure (or take any other mitigation action) as a result of the reliance on expected financial assistance from government relief programs or donations by other individuals has been reported as charity hazard (e.g., Browne and Hoyt, 2000; Raschky and Weck-Hannemann, 2007). As discussed in more detail by Raschky and WeckHannemann (2007) governmental aid may lead to the phenomenon that people underinsure or do not insure at all due to anticipated governmental assistance and private charity after a hazard event that caused considerable losses. In addition to an insufficient amount of insurance coverage, financial compensation by the government might result in an inefficient allocation of public funds, as Garrett and Sobel (2003) argued with respect to the federal disaster payments in the US which were found to be considerable politically motivated. Moreover, electoral factors were identified to influence the political response to disasters (Downton and Pielke, 2001) an aspect that has to be presumed to generally be also valid for European institutions.

Apart from the effects of adverse selection and moral hazard, the market penetration of (in fact considerably limited) insurance policies is relatively low in Austria due to the mechanism of loss compensation by the disaster fund. The disaster fund, regularised by the Federal Act related to the Disaster Fund of 1966 (Republik Österreich, 1966) provided the legal basis for the provision of national resources for (1) preventive actions to construct and maintain torrent and avalanche control measures, and (2) financial support for the Länder to enable them to compensate individuals and private enterprises for losses due to natural hazards in Austria. To provide financing of the disaster fund, tied surcharges were put on income taxes, wage taxes, taxes on capital yields, and corporate taxes. After being subject to several amendments, the legal act from 1966 was revised by the so-called Federal Act related to the Disaster Fund of 1996 (Republik Österreich, 1996). This law is still in force in the prevailing form. The budget of the disaster fund originates from a defined percentage (since 1996: 1.1\%) of the federal share on the income taxes, taxes on capital yield, and corporate taxes, which amounts to approximately $7 €$ for private households and $30 €$ for business entities per year (Vetters and Prettenthaler, 2004). Financial means which are not spent in a respective year are subject to a reserve. In accordance with the Austrian Court of Audit, the prescribed maximum reserves of the disaster fund is limited to 29 million $€$ (Republik Österreich, 1996).

To benefit from these compensations, people do need neither to pay written premiums nor do they have to contribute to the available funds otherwise - a strong incentive for more risky behaviour. Thus, the issue of third-party intervention, i.e., governmental funding, turned out to be a crucial aspect for a reduction of vulnerability in Austria. Furthermore, and this is presumably the second reason for low market penetration, the compensations paid out by the disaster 
fund are regularly shortened by (private) insurance compensations (Holub and Fuchs, 2009). Consequently, risk-aware people underwriting private natural hazard insurances are de facto worse off than less aware people not taking precaution actions, which leads again to decreasing demand in natural hazard insurance policies in Austria. Hence, people are vulnerable not due to political instability but due to the system of loss compensation institutionally established, and vulnerability occurs if institutions fail.

\section{Economic vulnerability}

Institutional vulnerability, as outlined above, leads in combination with structural vulnerability due to the impact of natural events on the built environment, but also on infrastructure facilities, to an economic vulnerability of values at risk exposed. Thus, resilience of individual or institutional proprietors is reduced. Thereby, a particular level or severity of a natural event becomes a hazard only in relation to existing human settings, i.e. settlements and infrastructure being set up in an area prone to mass movement processes such as torrent events or gravitational processes such as rock fall, a priori statement that is neither re-emerging nor unsurprising. Since hazards are so named because they cause economic damage and social disruption, the level and type of economic activity existing in an area - apart from the institutional framework of the society in that area including previous decisions about specific adjustments to the natural event in question - is involved in assessing the vulnerable character of an event. However, as already outlined in Russell (1970), attributing losses to a natural event alone might be misleading to quantify economic vulnerability unless these losses are relatively related to the economic activity in the studied region.

In Austria, a total number of 4894 damaging torrent events occurred between 1972 and 2004. For almost 4300 events the process type could be determined ex-post due to the event documentation carried out by the Austrian Torrent and Avalanche Control Service, resulting in a classification between floods $(0.3 \%)$, flooding with bedload transport (21.8\%), hyperconcentrated flows (49.2\%), and debris flows (28.7\%). The average direct loss per event due to these 4300 records amounted to approximately $170000 €$ (in 2008 values), and annually, losses do to torrent events amounted to around 25 million $€$. Approximately two third of the losses could be ascribed to buildings, and one third to infrastructure facilities. Within the period under investigation, 21 people were physically harmed and 49 people died ${ }^{3}$. In Fig. 3 the

\footnotetext{
${ }^{3}$ For comparison, during the same period 1972-2004, 1.48 million traffic accidents involving physical injury caused 53576 fatal casualties in Austria $(\sim 1600$ per year), 1.95 million persons were injured $(\sim 59000$ per year, Kuratorium für Verkehrssicherheit, 2005); and even 92 persons committed suicide every year (Statistik Austria, 2008a) - obviously traffic risk is
}

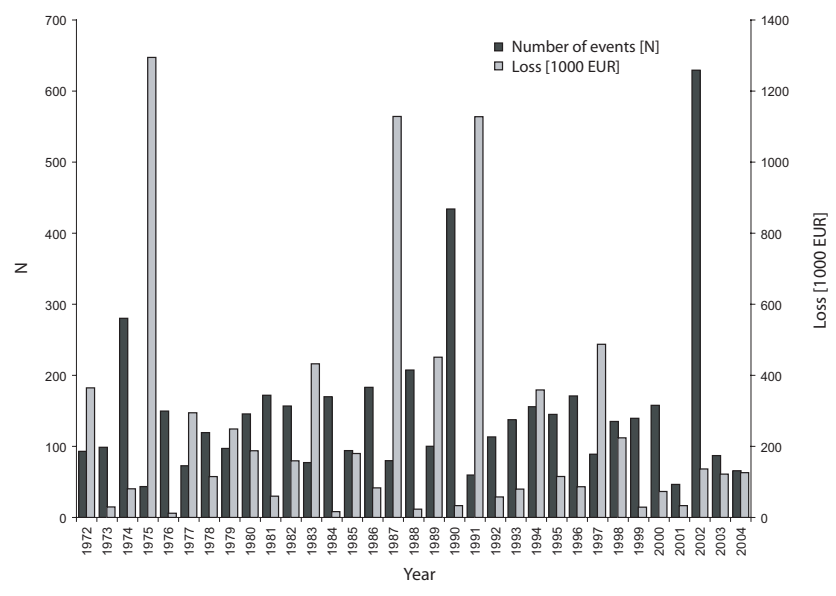

Fig. 3. Annual number of torrent events and distribution of resulting average losses for the period 1972-2004, N=4296. Data source: Austrian Torrent and Avalanche Control Service, reports from District Offices and Länder Sections.

annual distribution of the losses is shown, considerable cumulative damage exceeding 1 million $€$ per event occurred in 1975, 1978, and 1991. In contrast, in 1976 and 1984, the average damage per event summed up to $11000 €$ and $16000 €$ respectively. A considerable number of events was reported from 1974, 1990, and 2002 - leading to the conclusion that a high number of events not necessarily results in high losses, and vice versa.

A study on selected well-documented individual events and associated losses (in 2008 values) was carried out in order to differentiate the above-described overall values given for the period of 33 years. These data were made available through communities and the official Länder authorities responsible for the negotiation of governmental aid according to the above-mentioned Federal Act related to the Disaster Fund of 1996 (Republik Österreich, 1996). Within this Federal Act the allocation of resources is legally prescribed. A major budgetary item, also from the point of public perception, is the regular support of the Länder by the disaster fund in providing subsidies for disaster compensation to individuals and legal entities affected by natural hazards. Losses of private households and companies due to natural hazards are compensated to a certain degree by the disaster fund. The disaster fund, respectively the Republic of Austria, subsidises the Länder up to almost two third of that financial aid that was paid out by the Länder in order to support parties aggrieved by natural hazards. By these compensations, affected parties receive an indemnity up to a certain percentage of the overall amount of losses suffered:

1. Taking the torrent events of 1997 in the Wartschenbach catchment in the Eastern Alps within the community

subject to other moral concepts than risk resulting from torrent processes, and potential suicidal tendency is even not a real issue in reducing population vulnerability so far. 
of Nußdorf-Debant, next to the city of Lienz, Austria, as an example (Fuchs et al., 2007b), a total damage of 2 million $€$ was recognised by the official Länder authorities, which results in an average of approximately $50000 €$ per claimant (range $300 €-840000 €$ ). Due to legal regulations concerning subsidies of Länder compensation by the disaster fund, a share of only $52.6 \%$ was paid out on average as governmental aid to the aggrieved parties, the range was between $35 \%$ and $80 \%$ of the individually requested subsidy.

2. The torrential flood events of 2002 in the community of Maria Alm, eastwards of the city of Saalfelden, Austria, resulted in officially recognised losses of 1.5 million $€$ with an average of $22300 €$ per claimant. The individually accepted claims ranged between $100 €$ and $300000 €-$ in both cases for damage due to debris flows. An average share of nearly $60 \%$ was accepted for compensation by the disaster fund. The general range was between $25 \%$ and $100 \%$ of the individually requested subsidy, whereby the latter was not only applicable for minor damage but also for cases of constructive total loss. However, some claimants did not receive any subsidies since their losses where covered by insurance contracts.

3. The 2003 torrent events in Achenkirch-Unteraubach, westwards the lake Achensee resulted in an officially recognised total damage of $150300 €$ with an average of approximately $8000 €$ - these minor losses resulted in an average share of only $23.7 \%$ on average as governmental aid to the aggrieved parties; the individual range was between $0 \%$ and $45 \%$.

4. Comparing losses resulting from torrent events to other mountain hazards in Austria, the well-known 1999 avalanche event in the community of Galtür, Austria, was taken as an example (Heumader, 2000; Keiler, 2004; Keiler et al., 2006). A total damage of 7.45 million $€$ was officially recognised, resulting in an average of around $60000 €$ per claimant (including necessary funeral costs). The individually accepted claims ranged between $220 €$ for minor damage to mobile goods to 1.3 million $€$ for a completely destroyed building. An average share of around $60.0 \%$ was paid out as governmental support to the aggrieved parties. Some of the building damages, as well as the necessary transfer of decedents, were subsidised by $100 \%$ while other claimants did not receive any governmental aid from the disaster fund.

This exemplary listing provides strong evidence that losses tend to be event-specific, and thus individual losses might considerable exceed the average values reported for the whole country between 1972 and 2004. However, the listing highlights some issues related to the economic vulnerability of individuals towards mountain hazards.
Firstly, losses resulting from such hazards are a function of the individual impact of the event on elements at risk and the localisation of these elements at risk in relation to the spatial occurrence of this event (Fig. 2). Consequently, losses are spatially considerable variable, and therefore - due to the probability of occurrence of multiple events in the same location - also temporally variable, which makes an exact estimation of loss incurrence difficult. Consequently, as reported in the literature, the individual might underestimate its own vulnerability resulting from mountain hazards, in particular with respect to low-probability high-loss events. However, more detailed studies for the European Alps are still outstanding.

Secondly, losses resulting from such events range between some negligible hundreds of Euros, and several hundreds of thousands Euros in case of the complete destruction of buildings. Considering an average annual household income of around $27000 €$ in Austria ${ }^{4}$, such losses might result in an individual insolvency in dependence on the personal earning capacities of affected people. The latter is of particular importance since for private households natural hazards are not entirely subject to any comprehensive insurance system in Austria so far (Schieferer, 2006; Holub and Fuchs, 2009). Insurance coverage against losses resulting from natural hazards is only available so far with respect to losses occurring due to windstorm (defined as airflow with velocities $>60 \mathrm{~km} / \mathrm{h}$ ), hail, snow load (application of force due to naturally accumulated static snow packs), rockfall, and landslides (downslope movement of soil and rock masses along a subsurface shear plane; Schieferer, 2006). In contrast, apart from very limited coverage included in some household policies up to a sum between $3700 €$ and $15000 €$ per contract (Gruber, 2008), losses resulting from other mountain hazards are not insurable since the risk is not taken over by the insurance companies. Hence, the compensation mechanism of the disaster fund has to be considered as the only available instrument of institutionalised disaster aid in Austria (cf. Sect. 3). However, in most of the Länder, the compensation share paid out by the disaster fund is shortened by such limited private insurance compensation received by the claimant, which is connected to the issues of institutional vulnerability outlined above, and might in turn increase the economic vulnerability of persons affected fundamentally.

Thirdly, due to the Federal Act related to the Disaster Fund of 1996 (Republik Österreich, 1996) only a certain part of the

\footnotetext{
${ }^{4}$ According to the 2006 EU-SILC, Austrian households have a median household income of $27317 €$ a year, while $10 \%$ of households have less than $11230 €$ and $10 \%$ have more than $56266 €$ p.a. at their disposal (Statistik Austria, 2008b, c). EU-SILC is the only available data source on household income in Austria. Household income is calculated as the sum of all earned income in the household plus any income from capital and pensions as well as any social transfers. The net household income is obtained after deduction of taxes. The available net household income is then calculated by deducting and adding alimonies and other private transfers between the households.
} 
losses incurred might be eligible for compensation. Hence, a considerable share of the individual damage remains, and the related individual economic susceptibility might still be considerable high. This financial gap will only (at least partly) be closed if sufficient private disaster aid or donation by business entities is provided - turning the effects of a natural hazard into a typical charity hazard (Raschky and Weck-Hannemann, 2007). A prominent Austrian example therefore is the issuing of two stamps by the postal administration, one related to the avalanche winter of 1954 (when the postal administration was still governmental) and one after the flood events in 2006 (when the mail services where turned into a corporation, Fig. 4). With respect to the latter, some 100000 Euros had thus been collected from the population in order to support the reconstruction activities in the Austrian Marchfeld region due to the 2006 events, whereby the Austrian government already enacted an additional special law to support recovery from the flood events in 2005 (Republik Österreich, 2005) - supplementary to the continuously ongoing governmental support by the disaster fund ${ }^{5}$.

To conclude, societal and political decisions about reducing vulnerability do not necessarily meet the individual requirements of economic resilience. If losses due to natural hazards occur, the individual citizen is left with a considerable share of the damage due to missing guaranteed payments or liabilities evidenced by insurance policies - even if this might not mirror the economic preferences of individuals if they were asked. One major characteristic of any financial measure to reduce vulnerability towards mountain hazards in Austria is that the private sector does not supply them in a sufficient quantity given the potential economic benefits to society, therefore such measures have characteristics of public goods or common (pool) resources (Fuchs and McAlpin, 2005). In the economic theory of public goods it is assumed that individuals are aware of their preferences. Conversely, consumers might not always be aware of their preferences for financial measures to reduce vulnerability to natural hazards, which can be partly attributed to free supply and passive consumption of governmental subsidies for disaster compensation to individuals affected by natural hazards. Hence, the provision of protection against natural hazards to reduce economic vulnerability is commonly regarded as a governmental duty. However, in Austria, direct governmental interventions do not offer any explicit incentive for individuals to react vulnerability-minimising and to subsequently provide prevention measures on an individual basis.

\footnotetext{
${ }^{5}$ Additionally, a considerable amount of private and corporate donations is repeatedly collected by Austrian charity organisations, whereas the overall volume is hardly quantifiable. With respect to the 2002 inundations in Austria, the raised funds of registered relief organisations amounted to approximately 73 million $€$ cash (ÖIS, 2007) and around 10 million $€$ in-kind donations (Rotes Kreuz, 2003), whereas data that is more detailed is not accessible. By means of these donations, a sum of $7000 €$ was paid out on average per claimant to support reconstruction (Rotes Kreuz, 2003).
}

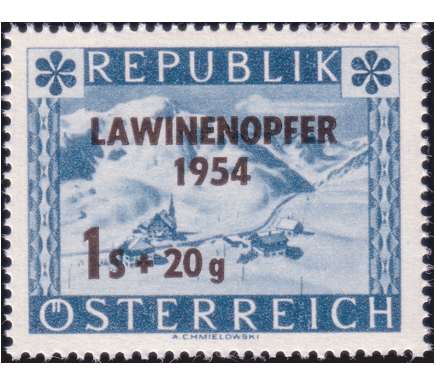

(a)

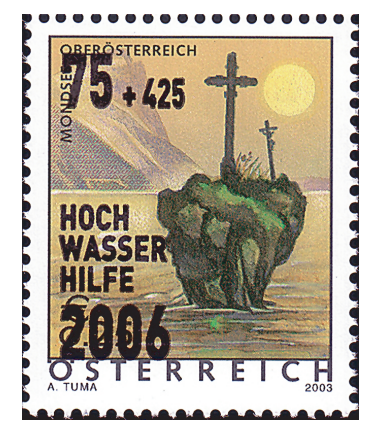

(b)
Fig. 4. Example for charity hazard in Austria: issuing of two stamps by the postal administration, (a) related to the avalanche winter of 1954 (when the postal administration was still governmental) and (b) after the flood events in 2006 (when the mail services where turned into a corporation). In the 1950 it had been sufficient to add a surcharge of $20 \%$ to the nominal value, while in 2006 , this surcharge was around $550 \%$. Reproduced with permission of the Austrian Postal Administration (Österreichische Post AG).

Since the competence of compensating losses that incurred due to natural hazards is allocated at the Länder level, the Länder are not only responsible for assessing damages but also for the loss payment. In general, after damage has been recorded by a locally-based expert commission, compensations are paid out by the respective federal province directly to the people affected. Nonetheless, there is neither any enforceable legal right for financial assistance, nor a certain level of guaranteed financial assistance resulting from the disaster fund act, as the examples indicated above have shown. Consequently, a considerable social vulnerability might result.

\section{Social vulnerability}

Social vulnerability can be defined as "the characteristics of a person or group and their situation that influence their capacity to anticipate, cope with, resist and recover from the impact of a natural hazard" (Wisner et al., 2004, p. 11). Hence, vulnerability is the inherent characteristics or qualities of social systems that create the potential for harm (Cutter et al., 2008). Defined in this way, vulnerability involves a combination of factors determining the degree of which an individual or the society is put at risk by a discrete event in nature, consequently, some groups are more prone to damage, loss and suffering in the context of torrent processes. Key variables explaining variations of impact include class, occupation, ethnicity, gender, disability and health status, age, and the nature and extent of social networks. For this reason, vulnerable groups are those that face considerable difficulties in reconstructing their livelihoods following disas- 
ters. Livelihood thereby is understood in its broadest sense by the respond an individual or social group has by a bundle of resources that can be used to recover from the adverse impact of a hazard event (Birkmann, 2006b). Such resources include information, cultural knowledge, social networks, legal rights, as well as physical resources (Cutter et al., 2003; Wisner et al., 2004) - and monetary reserves or any institutional settings.

Moreover, the concept of social sciences suggests that vulnerability has a social character and is not limited to the potential physical damage or to demographic determinants (Cardona, 2004). Influencing changes of social sciences' approaches in the theories to the vulnerability paradigm reflect a certain dynamic within the discipline. Starting with the non-political orientation of the Behaviouralists' approach in the 1980s and 1990s, which was based on denying any independent significance for mind and assuming that behaviour is determined by the environment, vulnerability research focused on understanding the ways in which individuals and groups responded to disaster events (Quarantelli, 1978). The role of social structures was attenuated since people were seen as influencing disasters in only a limited way (Pelling, 2003). Consequently, policy recommendations rather focused on disaster response and recovery than on reducing vulnerability. In contrast, the almost simultaneously upcoming neo-Marxist tradition in social sciences was to view disasters and underlying vulnerability as embedded within the social structures (Hewitt, 1983), allowing policy to incorporate preparedness in order to reduce susceptibility. Nonetheless, this approach was criticised for over-privileging economic class during the sets of analyses and for failing to identify the importance of individual agency in the production of vulnerability (Pelling, 2003).

Moreover, the concepts of social vulnerability show evidence for a changing characterisation. As Cutter (1996) stated, there are no distinctive and broadly agreed definitions of vulnerability in social sciences, in contrast, multiple definitions not only differ between several degrees of voluntariness when coping with natural hazards, but also consider individual as well as social influences, filtered by certain conditions that determine an individual's perception of risk. Consequently, with respect to the perception and assessment of vulnerability, the following chart can be spanned which describes the evaluation of vulnerability trough individuals as a result from cultural environment, perception of susceptibility and associated communication (Fig. 5). Thereby, the cultural environment provides the overall setting in terms of an origin of several social factors and historically rooted cultural ideals being both, individually and socially determined. Social factors amplify the perception of vulnerability, apart from familiarity and the behaviour of actors from authorities responsible for dealing with natural hazard risk due to the production of social norms through communication. Social factors determining the evaluation of vulnerability interact with individual factors, such as the degree of voluntariness when exposed to hazardous events, the personal experience resulting from previous events, concernment, attitude, adaptation strategies and processing of information. Additionally, issues of manageability of a certain threat and publicity are considered. The perception of the degree of vulnerability by the individual results from a perception filter set between the cultural environment and the natural hazard, depending on the severity of the event. Communication, on the other hand, is again result of a filtering of perception, and takes place between individuals or groups and between institutions and individuals. Communication shapes the evaluation of vulnerability. Thereby, target-oriented delivering of information on hazard and risk is of virtual importance to enable the evaluation of vulnerability and thus to create disaster-resilient communities (Fuchs et al., 2009). Finally, the evaluation of vulnerability leads to adjustments and coping strategies either to control the hazard or to reduce susceptibility.

As outlined in Downing et al. (2005), and according to Fig. 5, social vulnerability is characterised by (1) a differential exposure to stresses experienced or anticipated by different units exposed, (2) an inherent dynamics within vulnerable entities, and (3) a determination by social networks in social, political, economic, and environmental interactions. Vulnerability is rooted in the actions and multiple attributes of human actors, manifested simultaneously on more than one (temporal and spatial) scale, and influenced and driven by multiple stresses (see also Birkmann, 2006b) and communication. Consequently, the concept of social vulnerability is embedded into the overall concept of vulnerability - however defined - and refers to more than social characteristics of entities exposed to stressors since it also encompasses features of potential physical damage in the built environment (Cutter et al., 2003).

Numerous frameworks, conceptual models, and vulnerability assessment techniques have been developed to advance both the theoretical underpinnings and practical applications of the social vulnerability concept. The review of these is not a central issue within this paper, as they have recently been summarised e.g. by Adger (2006), Cutter et al. (2008), or McLaughlin and Dietz (2008) - all of which arguing by a social-ecological perspective and thus integrating humanenvironment interaction.

Human-environment interaction is of particular interest when questioning vulnerability resulting from mountain hazards. The concept originating from the social-ecological systems theory "reflects the idea that human action and social structures are integral to nature and hence any distinction between social and natural systems is arbitrary" (Adger, 2006, p. 268). Vulnerability is positioned as the degree to which a system is susceptible to adverse effects and the associated stress to which this system is unable to cope with. Therefore, the sensitivity and adaptive capacity of the system are key parameters, both of which could be defined as resilience of the system - the magnitude of disturbance that can be absorbed before a (social) system changes to a radically differ- 


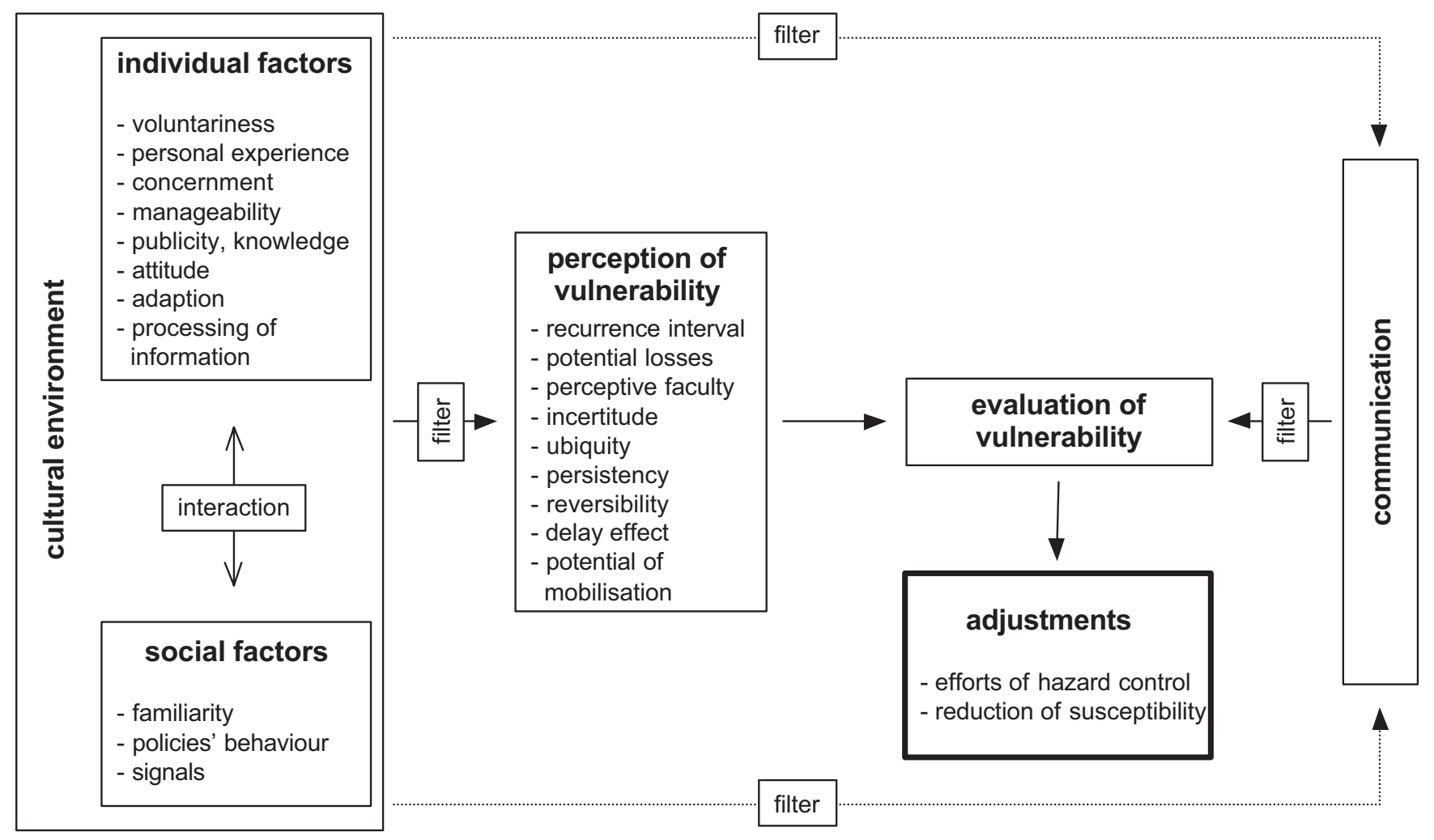

Fig. 5. Chart of vulnerability evaluation, illustrating the interaction between cultural environment, perception of vulnerability, and communication, finally leading to adjustments. These could either be efforts to control the hazard or to reduce vulnerability. Adopted and modified from a sketch in WBGU (1998, p. 169).

ent state (Holling, 1973), or the resistance of the system to disturbances and the associated speed of return to the equilibrium steady state or stability (Holling and Gunderson, 2002). By defining vulnerability as the counterpart of resilience, and consequently viewing both terms as separate but linked concepts, the two aspects of systems' stability have considerable different consequences for evaluating, understanding and managing mountain hazards. Both aspects of vulnerability focus on the dynamics of social structure when explaining vulnerability - either in terms of system flips, or in terms of systems' stability.

The first aspect of resilience, focusing on the amount of disturbance that can be sustained before a change in system control and structure occurs, refers to the ability of a society to cope with the impact of hazardous events unless the effects are as severe that a sudden change in livelihood conditions occurs, which results in political instability or even chaos. The second aspect concentrates on stability and is probably therefore more applicable within the framework of managing mountain hazards in Europe. Following the latter, even in case of extreme events, the vulnerability of the (social) system to stress is considerably low due to social networks, economic settings as well as institutional and po- litical factors, and consequently the speed of return to the equilibrium steady state, defined as the prevailing livelihood conditions, is fast. In other words, even if the magnitude of a hazardous event is high, the vulnerability is considerably low due to multiple compensation mechanisms installed in European societies, ranging from spreading risk to a larger community to governmental compensation and private donation. Therefore, ex-post recovery following an event is wellorganised, and the initial systems state is re-established immediately or with only little delay. Strong evidence therefore is provided by the relatively immediate return to normality in public life after the 1999 avalanche event affecting large regions of the Alps (Nöthiger et al., 2005), or after the 2005 and 2006 inundations in the Alpine foreland.

Following these arguments, it is not social inequity, missing access to education, or a question of gender that set the framework for social vulnerability to mountain hazards in Austria, in contrast it is the institutional framework composed from land use regulations, risk transfer mechanisms, individual desires and anticipated economic benefits. Consequently, this framework can be used to reduce social vulnerability to natural hazards. 
Land use regulations and regional development are a matter of the Austrian Länder, and related legal regulation is within the individual Länder responsibility (Hattenberger, 2006; Kanonier, 2006). Hence, for the regional as well as local planning level, multiple sets of laws with respect to land utilisation, land use planning and building development exist. Considering areas endangered by natural hazard processes, the traditional way to direct development activities in areas not exposed is an overall major principle to reduce vulnerability, but also a major task for local administrative bodies responsible, since areas for development are relatively scarce. Although higher-order regional planning and subordinated land development as main administrative tool are statutory, an implementation on the local level is not necessarily deducible. As a result of the particular interests of stakeholders involved, higher-order regulations might be solved with respect to individual local needs differently which might result in reduced resilience and therefore higher social vulnerability.

With respect to risk transfer mechanisms aiming to reduce social vulnerability, emphasis is placed on the compensation of resulted damages, e.g. by shifting the costs for compensation to an insurance pool or by disbursing public expenditures or governmental aids. As discussed in Sect. 3, such governmental aids play a major role in loss compensation in Austria since natural hazards are not subject to compulsory insurance so far. Since governmental compensation only covers a certain part of the monetary losses members of the society are suffering, a significant (residual) social susceptibility results. This susceptibility is regularly reduced by private donations, showing that inherent mechanisms within the societal network might be able to cope with the adverse effects of such events and therefore reduce vulnerability considerably. It is widely accepted that living in areas endangered by natural hazards belongs to the category of involuntary risks - even if this is only partly true since citizens and other people affected in principle could choose between different alternative locations for living and economic activities. Hence, vulnerability to natural hazards not only can be ascribed to the geographic location itself (hazards-of-place model of vulnerability, Cutter, 1996; Cutter et al., 2003), but is also a result from individual choices and preferences. Accordingly, voluntariness and awareness will become influencing factors in the near future with respect to the ongoing discussion on reducing social vulnerability.

\section{Discussion and conclusion}

To manage natural hazard risk, a broader understanding of the concept of vulnerability is needed in order to reduce losses resulting from hazardous events. Multiple conceptualisations of vulnerability exist that show inherent differences in underlying theories due to sectoral disciplinary foci.
Acknowledging these different roots of the multiple concepts of vulnerability it becomes apparent that only by a multidimensional approach the overall aim of reducing natural hazards risk can be achieved. It had been shown in the previous sections that disciplinary approaches in vulnerability assessment have intersections among each other, leading to the conclusion that structural, economic, institutional and social vulnerability are interdependent and interacting.

As a result, disciplinary paradigms of vulnerability, such as the exclusive determinism of social standing or the solely dependence of resilience on economic risk transfer mechanisms is not sufficient to comprehensively explain vulnerability to mountain hazards in Austria. Starting with the destructive effect of an event, values at risk will be damaged, which is structural vulnerability. Depending on the institutional setting of politics, e.g., the question of whether or not the loss incurred previously to elections, more or less public action will be undertaken in order to compensate affected people for the loss suffered. This compensation will in turn determine the economic vulnerability of these people concerned, and depending on the height of financial losses, the society within a specific region will experience more or less susceptibility to such hazardous events. Natural systems, social systems, and the built environment are interconnected and therefore the separation of different vulnerabilities is arbitrary. Human actions in mountain environments affect the state of vulnerability, and, in turn, the state of vulnerability shapes the possibilities of human action. More crucially, there are the differences of approach between those that see vulnerability in terms of variations in exposure to hazards and those that concentrate on variation in people's capacity to cope with hazards (Few, 2003). Studies in the former tend to "focus on the distribution of some hazardous condition, the human occupancy of this hazardous zone (...) and the degree of loss (life and property) associated with the occurrence of a particular event" (Cutter, 1996, p. 531). Studies in the latter tend to highlight the social construction of vulnerability or the socio-political process by which people are made vulnerable. Such different disciplinary concepts of vulnerability, and associated paradigms of vulnerability, have at least two common elements that could be used in order to better evaluate vulnerability (and its counterpart, resilience) to mountain hazards in Austria. Firstly, the concept of vulnerability is based on the integrated assessment of human-environment interaction, which is a geographical approach based on a social-ecological perspective; and secondly, vulnerability assessment should be based upon placebased studies in order to be able to evaluate the impacts of adverse effects on a regional level. The challenge in moving from individual disciplinary views to an interdisciplinary analysis of vulnerability by understanding the intersections and interactions of pure technical and pure socioscientific approaches should be undertaken. There is no doubt that values at risk are considerable susceptible if they are located in the run-out areas of mountain hazards. Vulnerability of a specific 
location is triggered by structural vulnerability of elements at risk affected, which has to be evaluated in-depth in order to provide robust values for quantifying the respective resulting risk (Fuchs et al., 2007b). Structural vulnerability is complemented by economic resilience, the institutional framework, and societal settings. Depending on the severity of the event and on additional aspect related to the temporal political situation, compensation is paid out that might reduce the individual financial vulnerability of people concerned considerably. However, unless loss compensation is solely based on the Disaster Fund Act, and thus considerable shares of the damage suffered remain with the claimants, institutional vulnerability results and economic vulnerability remains - therefore, society in Austria might still be remarkably vulnerable to mountain hazards. A reduction of institutional vulnerability is essential to result in a considerable reduction of societal vulnerability. One major step towards a more disasterresilient society is information, highlighting the interaction between prevention and precaution, as well as creating incentives for loss-reducing actions on the local level to reduce the structural vulnerability to natural hazards in Austria. As a consequence, technical as well as non-technical mitigation strategies continuously play a major role in reducing susceptibility to natural hazards.

To conclude, different concepts of vulnerability presented in the previous sections have different roots, different scientific objects, and therefore different informative values. Integrating in a holistic way the contributions of social sciences, natural sciences, politics, and economy would by no means (at the present stage) result in one individual integral method generally applicable, but in a concept offering complementary results that might be combined for a deeper understanding of hazard and risk (Fig. 6). Following the definition of vulnerability in natural sciences, a functional relation between the hazardous event (threat) and the values at risk exposed is the prerequisite for risk. Exposure defines the susceptibility of the values at risk to be affected by the hazard due to their location in the area of influence of the process and a lack of physical resistance (structural vulnerability). On the other hand, the concept of risk in social sciences is pillared by the intersection of the hazardous area and the general exposure of society as a whole; values at risk are understood as part of the society. Hence, social vulnerability is the underlying predisposition to suffer harm due to disadvantageous conditions, predefined characteristics and relative weaknesses related to social factors (Cardona, 2004). These two poles of vulnerability are linked by (1) economic vulnerability directed from structural vulnerability to social vulnerability, since individuals or societies cannot be vulnerable if they are not threatened, and (2) institutional vulnerability directed antipodal. Structural vulnerability results in loss, which in turn causes economic vulnerability to individuals or the society. Conversely, institutional settings of the society condition the height of structural vulnerability if coping strategies are developed and implemented. Both

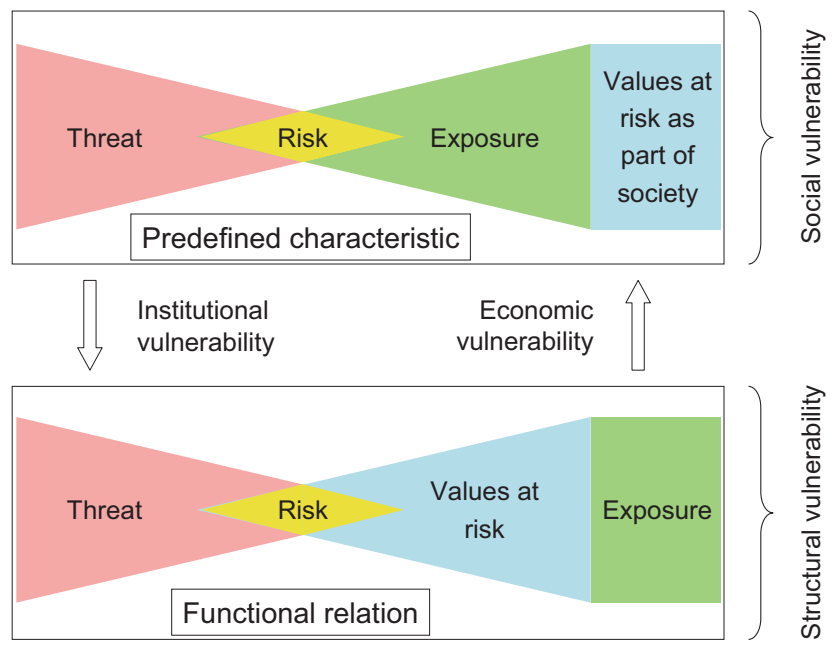

Fig. 6. Relationship between threat, values at risk, exposure, and risk defined for structural and social vulnerability in relation to economic and institutional vulnerability for European mountain regions. Adopted and modified from a sketch in Alexander (2002, p. 29).

concepts, the concept of vulnerability from a social sciences' perspective and from a natural sciences' perspective, convolute and supplement each other in a circular flow.

Acknowledgements. This work was supported by a research grant from the Austrian Science Fund ("Vulnerability to torrent events" - grant number L535-N10). The author greatly appreciates the comments of M. Keiler and M. Holub on an earlier draft of this manuscript, and the suggestions provided by two anonymous reviewers.

Edited by: J. Birkmann

Reviewed by: two anonymous referees

\section{References}

Adger, N.: Vulnerability, Global Environ. Chang., 16, 268-281, 2006.

Alexander, D.: Principles of emergency planning and management, Terra Publishing, Harpenden, 340 pp., 2002.

Alexander, D.: Vulnerability to landslides, in: Landslide hazard and risk, edited by: Glade, T., Anderson, M., and Crozier, M., John Wiley \& Sons, Chichister, 175-198, 2005.

Allen, K.: Vulnerability reduction and the community-based approach, in: Natural disasters and development in a globalising world, edited by: Pelling, M., Routledge, London, 170-184, 2003.

Arnell, N.: Flood insurance, in: Floods, edited by: Parker, D., Routledge, London, 412-424, 2000.

Atkisson, A., Petak, W., and Alesch, J.: Natural hazards exposures, losses and mitigation costs in the United States 1970- 
2000, Transactions - Wisconsin Academy of Sciences, Arts and Letters, 72, 106-112, 1984.

Barbolini, M., Cappabianca, F., and Sailer, R.: Empirical estimate of vulnerability relations for use in snow avalanche risk assessment, in: Risk Analysis IV, edited by: Brebbia, C., WIT, Southampton, 533-542, 2004.

Birkmann, J.: Indicators and criteria for measuring vulnerability: Theoretical bases and requirements, in: Measuring vulnerability to natural hazards, edited by: Birkmann, J., United Nations University Press, Tokyo, 55-77, 2006a.

Birkmann, J.: Measuring vulnerability to promote disaster-resilient societies: Conceptual frameworks and definitions, in: Measuring vulnerability to natural hazards, edited by: Birkmann, J., United Nations University Press, Tokyo, 9-54, 2006b.

BMLFUW [Bundesministerium für Land- und Forstwirtschaft, Umwelt und Wasserwirtschaft]: Richtlinien für die Wirtschaftlichkeitsuntersuchung und Priorisierung von Maßnahmen der Wildbach- und Lawinenverbauung gemäß $§ 3$ Abs. 2 Z 3 Wasserbautenförderungsgesetz, BMLFUW, Wien, 2005.

Borter, P.: Risikoanalyse bei gravitativen Naturgefahren, UmweltMaterialien 107/I, edited by: BUWAL, Bundesamt für Umwelt, Wald und Landschaft, Bern, 115 pp., 1999.

Brooks, N.: Vulnerability, risk and adaptation: A conceptual framework, Tyndall Centre for Climate Change Research Working Paper, 38, 1-16, 2003.

Browne, M. and Hoyt, R.: The demand for flood insurance: Empirical evidence, J. Risk Uncertainty, 20, 291-306, 2000.

Burton, I., Kates, R., and White, G.: The environment as hazard, Oxford University Press, New York, 240 pp., 1978.

Burton, I., Kates, R., and White, G.: The environment as hazard, Guilford Press, New York, 290 pp., 1993.

Cardona, O.: The need for rethinking the concepts of vulnerability and risk from a holistic perspective: A necessary review and criticism for effective risk management, in: Mapping vulnerability, edited by: Bankoff, G., Frerks, G., and Hilhorst, D., Earthscan, London, 37-51, 2004.

Commission of the European Communities: Directive 2007/60/EC of the European Parliament and of the Council of 23 October 2007 on the assessment and management of flood risks, http://eur-lex.europa.eu/LexUriServ/LexUriServ.do?uri= OJ:L:2007:288:0027:0034:EN:PDF (last access: 12 January 2009), 2007.

Crozier, M.: Magnitude-frequency concept, in: Encyclopaedia of geomorphology, edited by: Goudie, A., Routledge, London, 635-638, 2004

Cutter, S.: Vulnerability to environmental hazards, Prog. Hum. Geog., 20, 529-539, 1996.

Cutter, S., Holm, D., and Clark, L.: The role of geographic scale in monitoring environmental justice, Risk Anal., 16, 517-526, 1996.

Cutter, S.: The vulnerability of science and the science of vulnerability, Ann. Assoc. Am. Geogr., 93, 1-12, 2003.

Cutter, S., Boruff, B., and Shirley, W.: Social vulnerability to environmental hazards, Soc. Sci. Quart., 84, 242-261, 2003.

Cutter, S., Barnes, L., Berry, M., Burton, C., Evans, E., Tate, E., and Webb, J.: A place-based model for understanding community resilience to natural disasters, Global Environ. Chang., 18, 554563,2008
Downing, T., Aerts, J., Soussan, J., Barthelemy, O., Bharwani, S., Hinkel, J., Ionescu, C., Klein, R., Mata, L., Matin, N., Moss, S., Purkey, D., and Ziervogel, G.: Integrating social vulnerability into water management, SEI Working Paper and Newater Working Paper, 4, 1-32, 2005.

Downton, M. and Pielke, R.: Discretion without accountability: Policies, flood damage, and climate, Natural Hazards Review, 2, 157-166, 2001.

Eakin, H. and Luers, A.: Assessing the vulnerability of socialenvironmental systems, Annu. Rev. Env. Resour., 31, 365-394, 2006.

Fell, R.: Landslide risk assessment and acceptable risk, Can. Geotech. J., 31, 261-272, 1994.

Fell, R. and Hartford, D.: Landslide risk management, in: Landslide risk assessment, edited by: Cruden, D. and Fell, R., Balkema, Rotterdam, 51-109, 1997.

Few, R.: Flooding, vulnerability and coping strategies: Local responses to a global threat, Progress in Development Studies, 3, 43-58, 2003.

Frey, B.: Ökonomie ist Sozialwissenschaft, Vahlen, München, 233 pp., 1990

Fuchs, S., Bründl, M., and Stötter, J.: Development of avalanche risk between 1950 and 2000 in the Municipality of Davos, Switzerland, Nat. Hazards Earth Syst. Sci., 4, 263-275, 2004, http://www.nat-hazards-earth-syst-sci.net/4/263/2004/.

Fuchs, S., Keiler, M., Zischg, A., and Bründl, M.: The longterm development of avalanche risk in settlements considering the temporal variability of damage potential, Nat. Hazards Earth Syst. Sci., 5, 893-901, 2005, http://www.nat-hazards-earth-syst-sci.net/5/893/2005/.

Fuchs, S. and McAlpin, M. C.: The net benefit of public expenditures on avalanche defence structures in the municipality of Davos, Switzerland, Nat. Hazards Earth Syst. Sci., 5, 319-330, 2005 , http://www.nat-hazards-earth-syst-sci.net/5/319/2005/.

Fuchs, S., Thöni, M., McAlpin, M., Gruber, U., and Bründl, M.: Avalanche hazard mitigation strategies assessed by cost effectiveness analyses and cost benefit analyses - Evidence from Davos, Switzerland, Natural Hazards, 41, 113-129, 2007a.

Fuchs, S., Heiss, K., and Hübl, J.: Towards an empirical vulnerability function for use in debris flow risk assessment, Nat. Hazards Earth Syst. Sci., 7, 495-506, 2007b, http://www.nat-hazards-earth-syst-sci.net/7/495/2007/.

Fuchs, S., Dorner, W., Spachinger, K., Rochman, J., and Serrhini, K.: Flood risk map perception through experimental graphic semiology, in: Flood risk management. Research and practice, edited by: Samuels, P., Huntington, S., Allsop, W., and Harrop, J., Taylor \& Francis, London, 705-714, 2009.

Garrett, T. and Sobel, R.: The political economy of FEMA disaster payments, Econ. Inq., 41, 496-509, 2003.

Gruber, M.: Alternative solutions for public and private catastrophe funding in Austria, Nat. Hazards Earth Syst. Sci., 8, 603-616, 2008 , http://www.nat-hazards-earth-syst-sci.net/8/603/2008/.

Hattenberger, D.: Naturgefahren und öffentliches Recht, in: Recht im Naturgefahrenmanagement, edited by: Fuchs, S., Khakzadeh, L., and Weber, K., Studienverlag, Innsbruck, 67-91, 2006.

Heumader, J.: Die Katastrophenlawinen von Galtür und Valzur am 23. und 24. Februar 1999 im Paznauntal/Tirol, Internationales 
Symposion Interpraevent, Villach, 1, 397-410, 2000.

Hinshaw, R.: Living with nature's extremes: The life of Gilbert Fowler White, Johnson Books, Boulder, 339 pp., 2006.

Holling, C.: Resilience and stability of ecological systems, Annu. Rev. Ecol. Syst., 4, 1-23, 1973.

Holling, C. and Gunderson, L.: Resilience and adaptive cycles, in: Panarchy. Understanding transformations in human and natural systems, edited by: Gunderson, L. and Holling, C., Island Press, Washington, 25-63, 2002.

Holub, M. and Fuchs, S.: Mitigating mountain hazards in Austria Legislation, risk transfer, and awareness building, Nat. Hazards Earth Syst. Sci., 9, in review, 2009.

Holub, M., and Hübl, J.: Local protection against mountain hazards - state of the art and future needs, Nat. Hazards Earth Syst. Sci., 8, 81-99, 2008,

http://www.nat-hazards-earth-syst-sci.net/8/81/2008/.

Jaffee, D. and Russell, T.: Markets under stress: The case of extreme event insurance, in: Economics for an imperfect world, edited by: Arnott, R., Greenwald, B., Kanbur, R., and Nalebuff, B., MIT Press, Cambridge, 35-52, 2003.

Kanonier, A.: Raumplanungsrechtliche Regelungen als Teil des Naturgefahrenmanagements, in: Recht im Naturgefahrenmanagement, edited by: Fuchs, S., Khakzadeh, L., and Weber, K., Studienverlag, Innsbruck, 123-153, 2006.

Kasperson, R., Renn, O., Slovic, P., Brown, H., Emel, J., Goble, R., Kasperson, J., and Ratick, S.: The social amplification of risk: A conceptual framework, Risk Anal., 8, 177-187, 1988.

Kasperson, J., Kasperson, R., Turner, B., Hsieh, W., and Schiller, A.: Vulnerability to global environmental change, in: The social contours of risk, Volume II, Risk analysis, Corporations and the globalization of risk, edited by: Kasperson, J. and Kasperson, R., Earthscan, London, 245-285, 2005.

Kates, R.: Hazard and Choice Perception in Flood Plain Management, Research University of Chicago, Department of Geography, Chicago, Paper 78, 157 pp., 1962.

Keiler, M.: Development of the damage potential resulting from avalanche risk in the period 1950-2000, case study Galtür, Nat. Hazards Earth Syst. Sci., 4, 249-256, 2004,

http://www.nat-hazards-earth-syst-sci.net/4/249/2004/.

Keiler, M., Sailer, R., Jörg, P., Weber, C., Fuchs, S., Zischg, A., and Sauermoser, S.: Avalanche risk assessment - a multi-temporal approach, results from Galtür, Austria, Nat. Hazards Earth Syst. Sci., 6, 637-651, 2006,

http://www.nat-hazards-earth-syst-sci.net/6/637/2006/.

Kienholz, H., Krummenacher, B., Kipfer, A., and Perret, S.: Aspects of integral risk management in practice - Considerations with respect to mountain hazards in Switzerland, Österreichische Wasser- und Abfallwirtschaft, 56, 43-50, 2004.

Kimmerle, R.: Schadenanfälligkeit von Gebäuden gegenüber Wildbachgefahren, Master thesis, Universität Bern, Geographisches Institut, Bern, 120 pp., 2002.

Kuratorium für Verkehrssicherheit: Unfallstatistik 2004, Verkehr in Österreich, Kuratorium für Verkehrssicherheit, Wien, 37, 2005.

McLaughlin, P. and Diez, T.: Structure, agency and environment: Toward an integrated perspective on vulnerability, Global Environmental Change, 18, 99-111, 2008.

Mileti, D.: Disasters by design, Joseph Henry Press, Washington, 351 pp., 1999.
Nöthiger, C., Bürki, R., and Elsasser, H.: Naturgefahren und Tourismus in den Alpen, Geographica Helvetica, 60, 26-34, 2005.

North, D.: Institutions, institutional change and economic performance, Cambridge University Press, Cambridge, 152 pp., 1990.

ÖIS [Österreichisches Institut für Spendenwesen], Spendenbericht 2006, ÖIS, Wien, 2007.

Pelling, M.: Paradigms of risk, in: Natural disasters and development in a globalizing world, edited by: Pelling, M., Routledge, London, 3-16, 2003.

Priest, S., Clark, M., and Treby, E.: Flood insurance: the challenge of the uninsured, Area, 37, 295-302, 2005.

Raschky, P. and Weck-Hannemann, H.: Charity hazard - A real hazard to natural disaster insurance?, Environmental Hazards, 7, 321-329, 2007.

Raschky, P. A.: Institutions and the losses from natural disasters, Nat. Hazards Earth Syst. Sci., 8, 627-634, 2008, http://www.nat-hazards-earth-syst-sci.net/8/627/2008/.

Renn, O.: Concepts of risk: An interdisciplinary review - part 2: Integrative approaches, Gaia, 17, 196-204, 2008.

Republik Österreich: Bundesgesetz vom 9. September 1966 über den Katastrophenfonds, BGB1. Nr. 207/1966, 1966.

Republik Österreich: Hochwasseropferentschädigungs- und Wiederaufbau-Gesetz 2005 - HWG 2005, BGB1. I Nr. 112/2005 (Stammfassung), BGB1. I Nr. 13/2007 (Verlängerung bis Ende 2007), 2005.

Rotes Kreuz: ORF Hochwasser Soforthilfe, Factsheet Zwischenbilanz: old.roteskreuz.at/show_medium.php?mid=2469 (last access: 28 November 2008), 2003.

Russell, C.: Losses from natural hazards, Land Economics, 43, 383-393, 1970.

Schieferer, W.: Abwicklungsfragen im versicherungsrechtlichen Umfeld von Naturgefahren - Zukunftsperspektive der privaten Naturkatastrophen-Vorsorge nach dem Hochwasserereignis vom 23 August 2005, in: Recht im Naturgefahrenmanagement, edited by: Fuchs, S., Khakzadeh, L., and Weber, K., Studienverlag, Innsbruck, 115-122, 2006.

Scott, J.: Rational choice theory, in: Understanding contemporary society: Theories of the present, edited by: Browning, G., Halcli, A., and Webster, F., Sage, London, 126-138, 2000.

Starr, C.: Social benefit versus technological risk, Science, 165, 1232-1238, 1969.

Statistik Austria: Gestorbene in Österreich ab 1970: www.statistik.at/web_de/static/gestorbene_in_oesterreich_ab_ 1970_nach_todesursachen_und_geschlecht_021988.xls (last access: 28 November 2008), 2008a.

Statistik Austria: Verbrauchsausgaben: www.statistik.at/web_de/statistiken/soziales/ verbrauchsausgaben/konsumerhebung_2004_2005/index.html (last access: 28 November 2008), 2008b.

Statistik Austria: Average household income: www.statistik.at/ web_en/statistics/social_statistics/household_income/index.html (last access: 28 November 2008), 2008c.

Stötter, J. and Fuchs, S.: Umgang mit Naturgefahren - Status quo und zukünftige Anforderungen, in: Recht im Naturgefahrenmanagement, edited by: Fuchs, S., Khakzadeh, L., and Weber, K., Studienverlag, Innsbruck, 19-34, 2006.

Tobin, G. and Montz, B.: Natural hazards: Explanation and integration, Guilford Publications, New York, 388 pp., 1997. 
Ungern-Sternberg, T.: Efficient monopolies - The limits of competition in the European property insurance market, Oxford University Press, Oxford, 160 pp., 2004.

Varnes, D.: Landslide hazard zonation: A review of principles and practice, UNESCO, Paris, 60 pp., 1984.

Vetters, N. and Prettenthaler, F.: Extreme Wetterereignisse: Nationale Risikotransfersysteme im Vergleich, Universität Graz, Institut für Volkswirtschaftslehre, Graz, 28 pp., 2004.

WBGU [German Advisory Council on Global Change] (Ed.): World in transition: strategies for managing global environmental risks, Berlin, Springer, 359 pp., 1998.

White, G.: Human adjustment to floods: A geographical approach to the flood problem in the United States, University of Chicago, Department of Geography, Chicago, Research Paper 29, 225 pp., 1945.

White, G., Calef, W., Hudson, J., Mayer, H., Sheaffer, J., and Volk, D.: Changes in urban occupance of flood plains in the United States, Working University of Chicago, Department of Geography, Chicago, Paper 57, 235 pp., 1958.
White, G.: Choice of adjustment to floods, University of Chicago, Department of Geography, Chicago, Resource Paper 93, 149 pp., 1964.

Wilhelm, C.: Wirtschaftlichkeit im Lawinenschutz, Mitteilungen des Eidgenössischen Instituts für Schnee- und Lawinenforschung 54, Eidgenössisches Institut für Schnee- und Lawinenforschung, Davos, 309 pp., 1997.

Wisner, B.: The political economy of hazards: More limits to growth?, Environmental Hazards, 2, 59-61, 2000.

Wisner, B.: Assessment of capability and vulnerability, in: Mapping vulnerability. Disasters, development and people, edited by: Bankoff, G., Frerks, G., and Hilhorst, D., Earthscan, London, 183-193, 2004.

Wisner, B., Blaikie, P., Cannon, T., and Davis, I.: At risk. Natural hazards, people's vulnerability and disasters, Routledge, London, 469 pp., 2004. 